\title{
Article
}

\section{One Year of the COVID-19 Pandemic in Dental Medical Facilities in Germany: A Questionnaire-Based Analysis}

\author{
Stephan Zellmer ${ }^{1, *,+}$, Ella Bachmann ${ }^{2, *,+}$, Anna Muzalyova ${ }^{1}$, Alanna Ebigbo ${ }^{1}$, Maria Kahn ${ }^{1}$, \\ Claudia Traidl-Hoffmann ${ }^{3}$, Roland Frankenberger ${ }^{4}{ }^{\mathbb{D}}$, Fabian M. Eckstein ${ }^{5}$, Thomas Ziebart ${ }^{6}$, \\ Axel Meisgeier ${ }^{6}$, Helmut Messmann ${ }^{1}$, Christoph Römmele ${ }^{1,+}+\mathbb{D}$ and Tilo Schlittenbauer ${ }^{2,+}$
}

1 Department of Internal Medicine III-Gastroenterology and Infectious Diseases, University Hospital Augsburg, Stenglinstraße 2, 86156 Augsburg, Germany; anna.muzalyova@uk-augsburg.de (A.M.); alanna.ebigbo@uk-augsburg.de (A.E.); maria_kahn@gmx.de (M.K.);

Helmut.Messmann@uk-augsburg.de (H.M.); Christoph.Roemmele@uk-augsburg.de (C.R.)

2 Department of Oral and Maxillofacial Surgery, University Hospital Augsburg, Sauerbruchstraße 6, 86179 Augsburg, Germany; Tilo.Schlittenbauer@uk-augsburg.de

3 Department of Environmental Medicine, Faculty of Medicine, University of Augsburg, Neusäßer Straße 47, 86156 Augsburg, Germany; Claudia.Traidl-Hoffmann@uk-augsburg.de

4 Department of Operative Dentistry, Endodontics and Pediatric Dentistry, Campus Marburg, University Medical Center Giessen and Marburg, Georg-Voigt-Str. 3, 35039 Marburg, Germany; frankbg@med.uni-marburg.de

5 Department of Oral and Maxillofacial Surgery, Hannover Medical School, 30625 Hannover, Germany; Eckstein.Fabian@mh-hannover.de

6 Department of Oral and Maxillofacial Surgery, Campus Marburg, Philipps University Marburg and University Medical Center Giessen and Marburg, Baldingerstr, 35033 Marburg, Germany; ziebart@med.uni-marburg.de (T.Z.); mkg@med.uni-marburg.de (A.M.)

Citation: Zellmer, S.; Bachmann, E.; Muzalyova, A.; Ebigbo, A.; Kahn, M.; Traidl-Hoffmann, C.; Frankenberger, R.; Eckstein, F.M.; Ziebart, T.; Meisgeier, A.; et al. One Year of the COVID-19 Pandemic in Dental Medical Facilities in Germany: A Questionnaire-Based Analysis. Int. J. Environ. Res. Public Health 2022, 19, 175. https://doi.org/10.3390/ ijerph19010175

Academic Editor: Paul B. Tchounwou

Received: 14 November 2021 Accepted: 22 December 2021 Published: 24 December 2021

Publisher's Note: MDPI stays neutral with regard to jurisdictional claims in published maps and institutional affiliations.

Copyright: (C) 2021 by the authors. Licensee MDPI, Basel, Switzerland. This article is an open access article distributed under the terms and conditions of the Creative Commons Attribution (CC BY) license (https:// creativecommons.org/licenses/by/ $4.0 /)$.
* Correspondence: stephan.zellmer@uk-augsburg.de (S.Z.); ella.bachmann@uk-augsburg.de (E.B.); Tel.: +49-821-400-2351 (S.Z.)

+ These authors contributed equally to this work.

\begin{abstract}
Background: The COVID-19 pandemic forced healthcare workers to adapt to challenges in both patient care and self-protection. Dental practitioners were confronted with a potentially high possibility of infection transmission due to aerosol-generating procedures. This study aims to present data on healthcare worker (HCW) screening, infection status of HCWs, pre-interventional testing, the use of personal protective equipment (PPE) and the economic impact of the pandemic in dental facilities. (2) Methods: Dental facilities were surveyed nationwide using an online questionnaire. The acquisition of participants took place in cooperation with the German Society for Dentistry, Oral and Maxillofacial Medicine. (3) Results: A total of 1094 private practices participated. Of these, $39.1 \%$ treated fewer than 600 patients per quarter and 59.9\% treated over 600 patients per quarter. Pre-interventional testing was rarely performed in either small $(6.6 \%)$ or large practices $(6.0 \%)$. Large practices had a significantly higher incidence of at least one SARS-CoV-2-positive HCW than small practices $(26.2 \%$ vs. $14.4 \%, p<0.01)$. The main source of infection in small practices was the private environment, and this was even more significant in large practices $(81.8 \%$ vs. $89.7 \%, p<0.01)$. The procedure count either remained stable (34.0\% of small practices vs. $46.2 \%$ of large practices) or decreased by up to $50 \%$ (52.6\% of small practices vs. $44.4 \%$ of large practices). Revenue remained stable $(24.8 \%$ of small practices vs. $34.2 \%$ of large practices) or decreased by up to $50 \%(64.5 \%$ of small practices vs. $55.3 \%$ of large practices, $p=0.03)$. Overall, employee numbers remained stable $(75.5 \%$ of small practices vs. $76.8 \%$ of large practices). A vaccination readiness of $60-100 \%$ was shown in $60.5 \%$ $(n=405)$ of large practices and 59.9\% $(n=251)$ of small practices. (4) Conclusion: Pre-interventional testing in dental practices should be increased further. Economic challenges affected small practices as well as large practices. Overall, a steady employee count could be maintained. Vaccination readiness is high in dental practices, although with some room for improvement.
\end{abstract}

Keywords: COVID-19; dentistry; healthcare 


\section{Introduction}

Initially reported in Wuhan, China, at the end of 2019, the novel severe acute respiratory syndrome coronavirus type 2 (SARS-CoV-2) has spread rapidly, resulting in the World Health Organization officially declaring COVID-19 a pandemic on March 112020 [1]. Since the beginning of the COVID-19 pandemic, Germany has experienced multiple waves of infection [2].

To lower infection rates, precautionary measures have been implemented in many parts of the world, including social distancing, hygiene measures (washing hands, sneeze/ cough etiquette), face masks and room ventilation [3].

With millions of cases worldwide, the SARS-CoV-2 pandemic confronted healthcare workers with a multitude of challenges ranging from the care of infected patients and self-protection to economic challenges [4,5]. A redistribution of the work force and supplies was initiated, focusing mainly on intensive care units and COVID-19 hospital wards [6,7]. Personal protective equipment such as FFP2/3 masks were distributed in hospitals in the early phase of the pandemic. However, the situation was different in private practices, especially regarding dental health. Not partaking in COVID-19 patient care, dental health workers in Germany felt left out of the discussion regarding safety protocols and personal protective equipment, as well as economic compensation [8].

For dentists working in proximity to patients' uncovered facial areas during interventions, the risk of SARS-CoV-2 transmission via aerosols and droplets seemed especially high [9]. As aerosol-generating procedures (AGP) are a routine part of dental medicine, a closer inspection of infection rates and pre-interventional testing in this medical discipline is required.

Many dentists were aware of the necessity of using appropriate protective equipment early in the pandemic [10]. However, the recommendations of various dental societies on the use of PPE are partially inconsistent. Therefore, a closer look at the use of PPE is important [11].

In collaboration with the B-FAST project of the NUM (Network of University Medicine) the University Hospital Augsburg surveyed data on medical fields with aerosol-generating procedures (AGP), such as gastroenterology, otolaryngology, oral and maxillofacial surgery and dentistry.

This study aims to present data from a nationwide survey of dental facilities regarding the COVID-19 pandemic. In particular, the use of PPE, pre-interventional testing, healthcare worker screening, healthcare worker status and pandemic-related economic changes at the facilities were examined.

\section{Materials and Methods}

Based on expert discussion and a review of the current literature, a self-report online questionnaire with 64 items was designed (Supplementary Material Figure S1). This questionnaire was sent to private practices and clinics all over Germany and was available from 16 December to 24 January. Specialties with aerosol-generating procedures, such as gastroenterology, otolaryngology, oral and maxillofacial surgery and dentistry were included (Table 1). Topics covering infection of healthcare workers, personal protective equipment, pre-interventional testing, development of procedures, revenue, employee numbers and vaccination readiness during the COVID-19 pandemic were included. All questions were distributed between April 2020 and December 2020.

This publication focuses only on the subcategory of dentistry and compares the consequences of the pandemic for small practices and large practices. A small practice was defined as a practice treating at most 600 patients per quarter, and practices above this threshold were assigned to the category of large practices. The present paper focuses on the analysis of data provided by private practices only, as clinics were not sufficiently represented in the study. 
Table 1. Distribution by patients per quarter in private practices.

\begin{tabular}{cccc}
\hline & & $\mathbf{N}$ & $\mathbf{\%}$ \\
\hline Total & & 1114 & 100 \\
Hospital & 20 & 1.8 \\
Private Practice & 1094 & 98.2 \\
& Small $(<600 \mathrm{ppq})$ & 425 & 38.2 \\
& Large $(>600 \mathrm{ppq})$ & 669 & 60.1 \\
\hline
\end{tabular}

$\mathrm{N}$ : number of facilities; ppq: patients per quarter.

The nationwide study addressed heads of department and owners of dental facilities. Recruitment took place via the German Society for Dentistry and Oral Medicine (DGZMK). The online questionnaire could be answered from 16 December 2020 to 24 January 2021.

The statistical analysis for the dentistry subgroup was performed using IBM $^{\circledR}$ SPSS version 27.0 (IBM, New York City, NW, USA). Associations between categorical variables were assessed using the chi-squared test or Fisher's exact test where appropriate. Comparison of related samples was performed using the Friedman test. The significance level was set at $p<0.05$.

The study was conducted in accordance with the Declaration of Helsinki and the Good Clinical Practice (GCP) guidelines. A positive ethical evaluation of the study was obtained from the Ethics Committee of the Faculty of Medicine of the Technical University of Munich under the accession number 713/20 S-S.

\section{Results}

\subsection{Sample}

Overall, 1114 dental medical facilities filled out the online questionnaire. Among the participating dental medical facilities, the majority were private practices, whereas clinics constituted only $1.8 \%$ of the study population. Of the private practices, $38.2 \%(n=426)$ treated fewer than 600 patients per quarter and $59.9 \%(n=668)$ treated 600 patients or more per quarter (Table 1 ).

\subsection{Healthcare Worker Status}

The number of SARS-CoV-2-positive HCWs in private practices and hospital-based departments is shown in Table 2. Overall, 3.3\% $(n=396)$ of HCWs had a SARS-CoV-2 infection, confirmed via PCR testing. A significantly higher number of HCWs tested positive for SARS-CoV-2 in private practices compared to hospitals $(3.4 \%, n=382 \mathrm{vs.} 2.1 \%$, $n=14, p<0.01)$. There was no significantly relevant difference regarding the infection rate between small and large practices, although large practices reported a slightly higher proportion of infected HCWs $(3.5 \%$ vs. $3.1 \%, p=0.371)$.

Table 2. Distribution of SARS-CoV-2-positive healthcare workers in questioned private practices.

\begin{tabular}{cccccccc}
\hline & \multicolumn{2}{c}{$\begin{array}{c}\text { Employees } \\
\text { (Total) }\end{array}$} & & \multicolumn{2}{c}{$\begin{array}{c}\text { Employees } \\
\text { (SARS-CoV-2-Positive) }\end{array}$} \\
\hline & N & HCW & N & HCW & Rate of SARS-CoV-2-Positive HCWs & $p$ \\
\hline Hospital & 20 & 670 & 6 & 14 & 2.1 & 3.4 & 3.1 \\
Private Practice & 1094 & 11,334 & 235 & 382 & 3.5 & n.s. \\
Small (<600 ppq) & 425 & 2534 & 61 & 78 & 3.3 & \\
Large ( $>600$ ppq) & 669 & 8800 & 175 & 304 & 396 & & \\
Overall & 1114 & 12,004 & 241 & 396 & & \\
\hline
\end{tabular}

$\mathrm{N}$ : number of facilities; HCW: healthcare worker; ppq: patients per quarter.

\subsection{Source of Infection}

In the following section, the assumed source of infection among HCWs identified by the heads of the facilities (heads of departments in hospitals or private practice owners) is specified. Small dental practices had at least one SARS-CoV-2-positive case among HCWs 
less frequently than large practices $(14.4 \%, n=61$ vs. $26.2 \%, n=175, p<0.01)$ (Table 3$)$. In small practices $(91.8 \%, n=56)$ as well as large private practices $(89.7 \%, n=157)$, the main source of infection was the private environment. However, small practices reported the private environment to be the primary source of infection significantly more often than large practices $(p<0.01)$. In addition, $10.4 \%(n=7)$ of small practices reported an unclear origin of transmission, and $10.4 \%(n=7)$ named the workplace without patient contact as the source of infection. In $12.6 \%(n=22)$ of cases, large practices could not identify the source of infection.

Table 3. Assumed source of infection for healthcare workers.

\begin{tabular}{|c|c|c|c|c|c|c|}
\hline & & \multicolumn{4}{|c|}{ Private Practices } & \multirow[b]{3}{*}{$\mathbf{p}$} \\
\hline & & \multicolumn{2}{|c|}{$\begin{array}{c}\text { Small } \\
(<600 \mathrm{ppq})\end{array}$} & \multicolumn{2}{|c|}{$\begin{array}{c}\text { Large } \\
(>600 \mathrm{ppq})\end{array}$} & \\
\hline & & $\mathbf{N}$ & $\%$ & $\mathbf{N}$ & $\%$ & \\
\hline Total & & 425 & 100.0 & 669 & 100.0 & \\
\hline $\begin{array}{c}\text { Facilities with no } \\
\text { SARS-CoV-2-positive HCW }\end{array}$ & & 364 & 85.6 & 494 & 73.8 & \\
\hline \multirow[t]{6}{*}{$\begin{array}{c}\text { Facilities with } \\
\text { SARS-CoV-2-positive HCWs }\end{array}$} & & 61 & 14.4 & 175 & 26.2 & $<0.01$ \\
\hline & During interventions & 0 & 0.0 & 3 & 1.7 & n.s. \\
\hline & At work (with patient contact) & 0 & 0.0 & 4 & 2.3 & n.s. \\
\hline & At work (without patient contact) & 7 & 11.5 & 7 & 4.0 & n.s. \\
\hline & Unclear origin & 7 & 11.5 & 22 & 12.6 & n.s. \\
\hline & Private environment & 56 & 91.8 & 157 & 89.7 & $<0.01$ \\
\hline
\end{tabular}

$\mathrm{N}$ : number of facilities; HCW: healthcare worker; ppq: patients per quarter. It was possible to select more than one source of infection.

\subsection{Pre-Interventional Testing}

It was reported that $93.4 \%(n=397)$ of small practices and $94.0 \%(n=629)$ of large practices performed no pre-interventional testing (Table 4). If testing occurred, small practices $(n=20,4.7 \%)$ as well as large practices $(n=25,3.7 \%)$ most often used internal (carried out by the practices themselves) antigen testing (Table 4).

Table 4. Methods and distribution of pre-interventional testing of outpatients and inpatients.

\begin{tabular}{|c|c|c|c|c|c|c|}
\hline & \multicolumn{6}{|c|}{ Private Practices } \\
\hline & & \multicolumn{2}{|c|}{ Small (<600 ppq) } & \multicolumn{2}{|c|}{ Large (>600 ppq) } & \multirow[b]{2}{*}{$p$} \\
\hline & & $\mathbf{N}$ & $\%$ & $\mathbf{N}$ & $\%$ & \\
\hline \multirow[t]{6}{*}{ Total } & & 425 & 100 & 669 & 100 & n.s. \\
\hline & Internal PCR & 0 & 0.0 & 4 & 0.6 & n.s. \\
\hline & Internal antigen & 20 & 4.7 & 25 & 3.7 & n.s. \\
\hline & External PCR & 6 & 1.4 & 5 & 0.7 & n.s. \\
\hline & External antigen & 2 & 0.5 & 6 & 0.9 & n.s. \\
\hline & No testing & 397 & 93.4 & 629 & 94.0 & n.s. \\
\hline
\end{tabular}

$\mathrm{N}$ : number of facilities; PCR: polymerase chain reaction; ppq: patients per quarter.

\subsection{Personal Protective Equipment}

FFP2/3 use rose over the course of time in small practices $(24.9 \%$ in Q2 to $52.8 \%$ in $\mathrm{Q} 4, p<0.01)$ as well as in large practices $(28.8 \%$ in $\mathrm{Q} 2$ to $58.9 \%$ in $\mathrm{Q} 4, p<0.01)$, while MNP use (medical mouth-nose protection) declined in both small (69.9\% in Q2 to 52.8\% in Q4, $p<0.01)$ and large practices $(66.5 \%$ in Q2 to $47.2 \%$ in Q4, $p<0.01)$. An increase was also observed in room ventilation in small practices $(50.6 \%$ in $\mathrm{Q} 2$ to $75.8 \%$ in $\mathrm{Q} 4, p<0.01)$ and 
in large practices (45.6\% in Q2 to 74.6\% in Q4, $p<0.01$ ). The use of gowns remained low in small (5.9\% in Q2 to 7.1\% in Q4, $p=0.194)$ and large practices (4.8\% in Q2 to 5.5\% in $\mathrm{Q} 4, p=0.275)$. The use of goggles remained at a constant level in small practices $(80.9 \%$ in $\mathrm{Q} 2$ to $87.5 \%$ in $\mathrm{Q} 4, p<0.01)$ and in large practices $(77.4 \%$ in $\mathrm{Q} 2$ to $81.3 \%$ in $\mathrm{Q} 4, p<0.01)$ (Figure 1).
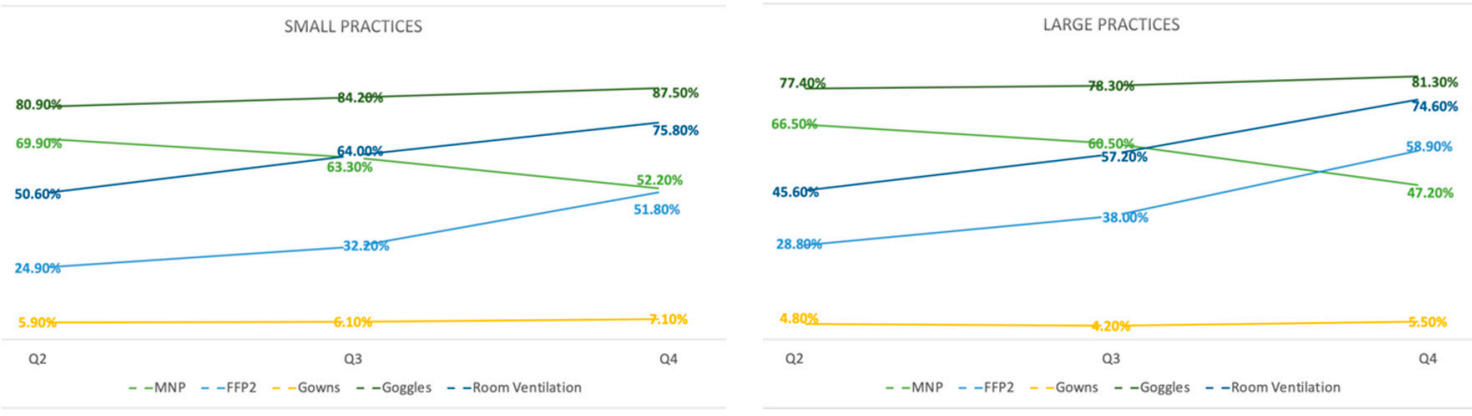

Figure 1. Personal protective equipment: usage from Q2 to Q4.

\subsection{Types of Procedures}

The proportion of aerosol-generating procedures was less than $20 \%$ in $48.2 \%(n=205)$ of small practices and $43.8 \%(n=293)$ of large practices up to the end of 2020 (Table 5). Only $1.9 \%(n=8)$ of small practices and $1.5 \%(n=10)$ of large practices reported performing a proportion of aerosol-generating procedures of more than $80 \%$.

Table 5. Share of aerosol-generating procedures and use of rubber dam.

\begin{tabular}{|c|c|c|c|c|c|c|}
\hline & \multirow{3}{*}{$\begin{array}{c}\text { Share of Procedures } \\
\% \%\end{array}$} & \multicolumn{4}{|c|}{ Private Practices } & \multirow{3}{*}{$p$-Value } \\
\hline & & \multicolumn{2}{|c|}{ Small (<600 ppq) } & \multicolumn{2}{|c|}{ Large ( $>600$ ppq) } & \\
\hline & & $\mathbf{N}$ & $\%$ & $\mathbf{N}$ & $\%$ & \\
\hline \multirow{6}{*}{$\begin{array}{l}\text { Aerosol- } \\
\text { generating } \\
\text { procedures }\end{array}$} & & 425 & 100 & 669 & 100 & \\
\hline & $<20$ & 205 & 48.2 & 293 & 43.8 & n.s. \\
\hline & $20-<40$ & 152 & 35.8 & 254 & 38.0 & n.s. \\
\hline & $40-<60$ & 48 & 11.3 & 91 & 13.6 & n.s. \\
\hline & $60-<80$ & 12 & 2.8 & 21 & 3.1 & n.s. \\
\hline & $>80$ & 8 & 1.9 & 10 & 1.5 & n.s. \\
\hline \multirow[t]{6}{*}{ Rubber dam } & & 425 & 100 & 669 & 100 & \\
\hline & $<20$ & 283 & 66.6 & 479 & 71.6 & n.s. \\
\hline & $20-<40$ & 69 & 16.2 & 111 & 16.6 & n.s. \\
\hline & $40-<60$ & 36 & 8.5 & 47 & 7.0 & n.s. \\
\hline & $60-<80$ & 20 & 4.7 & 18 & 2.7 & n.s. \\
\hline & $>80$ & 17 & 4.0 & 14 & 2.1 & n.s. \\
\hline
\end{tabular}

N: number of facilities; ppq: patients per quarter.

The majority of small practices $(n=283,66.6 \%)$ as well as the majority of large practices $(n=479,71.6 \%$ ) reported using a rubber dam in less than $20 \%$ of procedures.

\subsection{Air Ventilation Systems}

In large practices, ventilation systems were used more often than in small practices (50.9\%, $n=339$ vs. $43.7 \%, n=185, p<0.05$ ) (Table 6). No significant difference could be identified regarding the use of different ventilation systems. 
Table 6. Use of air ventilation systems.

\begin{tabular}{|c|c|c|c|c|c|c|}
\hline & & \multicolumn{4}{|c|}{ Private Practices } & \multirow{3}{*}{$p$-Value } \\
\hline & & \multicolumn{2}{|c|}{ Small $(<600$ ppq) } & \multicolumn{2}{|c|}{ Large (>600 ppq) } & \\
\hline & & $\mathbf{N}$ & $\%$ & $\mathbf{N}$ & $\%$ & \\
\hline Total & & 423 & 100 & 666 & 100 & \\
\hline \multirow[t]{6}{*}{ Yes } & & 185 & 43.7 & 339 & 50.9 & $<0.05$ \\
\hline & $\begin{array}{l}\text { Air handling units (AHU) in the } \\
\text { recirculation mode }\end{array}$ & 25 & 13.5 & 60 & 17.7 & n.s. \\
\hline & $\begin{array}{l}\text { Air handling units (AHU) with air } \\
\text { filter (e.g., HEPA filter) } \\
\text { with/without recirculation mode }\end{array}$ & 71 & 38.4 & 136 & 40.1 & n.s. \\
\hline & $\begin{array}{l}\text { Fans/mobile air conditioners } \\
\text { without air filter/fan heaters }\end{array}$ & 53 & 28.6 & 78 & 23.0 & n.s. \\
\hline & Other types & 24 & 13.0 & 38 & 11.2 & n.s. \\
\hline & Unknown & 12 & 6.5 & 27 & 8.0 & n.s. \\
\hline No & & 237 & 56.0 & 319 & 47.9 & $<0.01$ \\
\hline Unknown & & 1 & 0.2 & 8 & 1.2 & n.s. \\
\hline
\end{tabular}

N: number of facilities; ppq: patients per quarter. Not all participants answered this question.

\subsection{Development of Procedures}

During the COVID-19 pandemic, the number of procedures performed remained stable in $34.0 \%(n=144)$ of small practices and in $46.2 \%(n=307)$ of large practices (Table 7$)$. A decrease of less than $50 \%$ could be observed significantly more often in small private practices than in large private practices $(52.6 \%, n=223$ vs. $44.4 \%, n=295, p<0.01)$.

Table 7. Development of procedures.

\begin{tabular}{ccccccc}
\hline & \multicolumn{7}{c}{ Private Practices } \\
\hline & Small $(<\mathbf{6 0 0} \mathbf{p p q})$ & Large $(>\mathbf{6 0 0} \mathbf{p p q})$ & \\
\hline \multirow{2}{*}{ Total } & $\mathbf{N}$ & $\mathbf{\%}$ & $\mathbf{N}$ & $\mathbf{\%}$ & $\boldsymbol{p}$ \\
\hline \multirow{2}{*}{ Increase over $50 \%$} & 424 & 100.0 & 664 & 100.0 & \\
\hline & 10 & 2.4 & 11 & 1.7 & n.s. \\
\hline Increase less than $50 \%$ & 24 & 5.7 & 45 & 6.8 & n.s. \\
\hline Stable & 144 & 34.0 & 307 & 46.2 & $<0.01$ \\
\hline & Decrease less than $50 \%$ & 223 & 52.6 & 295 & 44.4 & $<0.01$ \\
\hline & Decrease over $50 \%$ & 23 & 5.4 & 6 & 0.9 & $<0.01$ \\
\hline
\end{tabular}

$\mathrm{N}$ : number of facilities; ppq: patients per quarter. Not all participants answered this question.

\subsection{Economic Revenue and Employee Numbers}

None of the large practices reported a revenue increase of over $50 \%$ (Table 7), whereas $0.7 \%(n=3)$ of small private practices did so. At $8.8 \%(n=59)$, a significantly higher number of large practices experienced an increase of less than $50 \%$ than small practices $(3.8 \%, n=16$, $p<0.01)$. A stable revenue was reported significantly more often by large practices $34.2 \%$ $(n=228)$ than by small practices $24.8 \%(n=105, p<0.01)$. A decrease in revenue of less than $50 \%$ was observed in $55.3 \%(n=369)$ of large practices and significantly more often in small practices, at $64.5 \%(n=273, p<0.01)$ (Table 8$)$. 
Table 8. Development of procedures.

\begin{tabular}{|c|c|c|c|c|c|c|}
\hline & & \multicolumn{4}{|c|}{ Private Practice } & \multirow[b]{3}{*}{$p$} \\
\hline & & \multicolumn{2}{|c|}{ Small (<600 ppq) } & \multicolumn{2}{|c|}{ Large (>600 ppq) } & \\
\hline & & $\mathbf{N}$ & $\%$ & $\mathbf{N}$ & $\%$ & \\
\hline Revenue & & 423 & 100 & 667 & 100 & \\
\hline & Increase over $50 \%$ & 3 & 0.7 & 0 & 0 & n.s. \\
\hline & Increase less than $50 \%$ & 16 & 3.8 & 59 & 8.8 & $<0.01$ \\
\hline & Stable & 105 & 24.8 & 228 & 34.2 & $<0.01$ \\
\hline & Decrease less than $50 \%$ & 273 & 64.5 & 369 & 55.3 & $<0.05$ \\
\hline & Decrease over $50 \%$ & 26 & 6.1 & 11 & 1.6 & $<0.01$ \\
\hline Employees & & 425 & 100 & 669 & 100 & \\
\hline & Increase & 26 & 6.1 & 68 & 10.2 & $<0.05$ \\
\hline & Stable & 321 & 75.5 & 514 & 76.8 & n.s. \\
\hline & Decrease & 78 & 18.4 & 87 & 13 & $<0.05$ \\
\hline
\end{tabular}

$\mathrm{N}$ : number of facilities; ppq: patients per quarter. Not all participants answered this question.

Employee numbers remained stable in $76.8 \%(n=514)$ of large practices and $75.7 \%$ $(n=321)$ of small practices. A significant increase in the size of the workforce was reported by $10.2 \%(n=68)$ of large and $6.1 \%(n=26)$ of small practices $(p<0.05)$ compared to a significant decrease in numbers in $13.0 \%(n=87)$ of large and $18.4 \%(n=78)$ of small practices $(p<0.05)($ Table 8$)$.

\subsection{Vaccination Readiness}

Table 9 shows the vaccination readiness in small and large practices. Vaccination readiness in the range between 80 and $100 \%$ was reported significantly more often in small than in large practices $(37.6 \%, n=160$ vs. $28.7 \%, n=192, p<0.01)$. Large practices reported vaccination readiness of $60-<80 \%$ significantly more often than small practices $(31.8 \%$, $n=213$ vs. $21.4 \%, n=9, p<0.01$ ). The remaining vaccination readiness rates of $40-<60 \%$, $20-<40 \%$, and $<20 \%$ were distributed among large and small practices relatively equally.

Table 9. Vaccination readiness by size of the private practice.

\begin{tabular}{|c|c|c|c|c|c|c|}
\hline & \multicolumn{6}{|c|}{ Private Practice } \\
\hline & \multirow{2}{*}{$\begin{array}{c}\text { Vaccination } \\
\text { Readiness } \\
\%\end{array}$} & \multicolumn{2}{|c|}{ Small (<600 ppq) } & \multicolumn{2}{|c|}{ Large (>600 ppq) } & \multirow[b]{2}{*}{$p$} \\
\hline & & $\mathbf{N}$ & $\%$ & $\mathbf{N}$ & $\%$ & \\
\hline \multirow[t]{6}{*}{ Total } & & 425 & 100 & 669 & 100 & \\
\hline & $<20$ & 27 & 6.4 & 40 & 6.0 & n.s. \\
\hline & $20-<40$ & 46 & 10.8 & 70 & 10.5 & n.s. \\
\hline & $40-<60$ & 101 & 23.8 & 154 & 23.0 & n.s. \\
\hline & $60-<80$ & 91 & 21.4 & 213 & 31.8 & $<0.01$ \\
\hline & 80-100 & 160 & 37.6 & 192 & 28.7 & $<0.01$ \\
\hline
\end{tabular}

N: number of facilities; ppq: patients per quarter.

\section{Discussion}

This study presents the results of a nationwide survey of dental facilities and reports on the data regarding pre-interventional testing, $\mathrm{HCW}$ infection rates, use of personal protective equipment, economic turnover, and staff development during the COVID-19 pandemic. A total of 1094 private practices and 20 dental clinics participated. To place this in context, there are about 87 dentists per 100,000 inhabitants in Germany; about 50,000 dental practices in total and an unknown number of dental clinics [12]. 
Considering the proximity of dental HCWs to the facial area of the patient during interventions and the utilization of instruments generating aerosols and droplets containing potentially infectious material, patient testing beforehand could be an effective measure to decrease the risk of infection transmission [9]. However, only a small number of practices reported any pre-interventional testing, thus demonstrating a deficit in testing strategies in everyday dental patient care. Within these limited testing routines for patients, internal antigen testing was the most common in all practices. However, antigen tests have been shown to provide results that are not as accurate as those of PCR tests [13].

Taking this into account, the German Society for Dentistry, Oral and Maxillofacial Medicine (DGZMK) developed an S1 guideline in September 2020 regarding patient care during the COVID-19 pandemic. This guideline included no recommendation for preinterventional testing; however, it addressed the possible necessity of implementing testing protocols depending on regional incidence rates [14]. Nevertheless, screening strategies are a cornerstone of SARS-CoV-2 infection prevention [15].

SARS-CoV-2 infections among HCWs occurred more often in large practices than in small practices. In both small and large practices, the rate of SARS-CoV-2-positive HCWs was significantly higher than in dental clinics [16]. Possibly, insufficient pre-interventional testing in practices could have been responsible for this. The S1 guideline of the DGZMK stated a lack of data on healthcare worker screening, so no consensus has been found to date [13]. Although this study shows that the main source of infection seems to be private and home environments, any possibility of reducing the spread of infection should be seized. A significant upward trend in the use of FFP2/3 masks in all practices, as well as in room ventilation, was observed. Safety goggles, already being used in many dental offices, showed slightly increased use in all practices. A similar positive trend in the usage of FFP2/3 masks or goggles could also be identified in studies from Poland, Turkey and Italy $[17,18]$.

The DGZMK guideline recommends wearing a standard MNP during all patient interventions, whereas further protective measures such as FFP2/3 masks are only required when treating suspected or confirmed SARS-CoV-2 cases. Consequently, SARS-CoV-2positive patients should only be treated as emergency cases, preferably in dental clinics with more resources, and they should be separated from other patients to avoid crosscontamination [13].

In this study, large practices reported using air ventilation systems significantly more often than small practices, with no significant difference in the type of air ventilation system used. Although the use of ventilation systems initially had only a minor role in the recommendations of various dental societies for managing COVID-19, by the end of 2020 more than half of large practices reported using air ventilation systems $[11,14,19]$. Several studies have demonstrated the positive effect of ventilation systems on aerosol exposure in rooms in dental clinics and dental medical practices [20,21]. Even aspiration systems, which were not investigated in this study, may play a role in the reduction of aerosols in dental medical facilities [22]. Furthermore, it has been shown that the type of aspiration system used influences the prevalence of SARS-CoV-2 infections [23]. Therefore, attention should be given to using ventilation systems and adequate aspiration systems.

The economic effects of the COVID-19 pandemic on the dental health sector did not go unnoticed. A decline in revenue of up to $50 \%$ was reported in the majority of practices, while about a quarter of small practices and approximately one third of larger practices registered no economic change. An increase in revenue of up to 50\% was reported in 3.8\% of small and $8.8 \%$ of large practices. This increase in income contrasts with a simulation by Schwendicke et al. which predicted a substantial loss of revenue for both dental medical practices and dental clinics [24]. This increase could correlate with the overall decrease in revenue in dental practices. To some extent, larger practices may have been handling the situation differently compared with smaller practices [25]. With possibly more staff and financial resources to support pandemic-related measures, some larger practices may have been able to offer treatment while other dental practices had to shut down or decrease 
their patient flow, thereby taking on new patients and subsequently profiting indirectly. In addition, the guideline of the German Society of Dentistry recommended that suspected or confirmed COVID-19 cases should preferably be treated in specialized facilities, thereby benefitting individual practices [14]. Following the same trend, 52.6\% of small practices and $44.4 \%$ of large practices suffered a decline in the number of procedures of up to $50 \%$. A survey conducted in June 2020 at the waning of the first wave reported a reduction in workload of about $60 \%$ in both small and large dental facilities [25]. The difference with respect to the data of the present study, which were collected during the second wave of the pandemic, could be explained by a change in the way the pandemic was handled. An increase in procedures of up to $50 \%$ was seen in a small number of practices. Even given the fluctuations in revenue and procedure counts, most of the small and large practices were able to maintain a stable staff size. Compensation for loss of income was discussed in a press statement by the KZVB on 22 March 2021, regarding financial support for dentists up to a maximum of EUR 275,000,000 as from 1 April 2021 [26].

In this study, we were able to demonstrate a high vaccination readiness in most practices. However, no further inquiry was made containing interest in certain manufacturers or types of vaccines. While the initial hesitation towards the newly developed vaccines was widespread, vaccination rates increased steadily after their introduction and after vaccines became generally available for the population as a whole [27].

As in all cross-sectional studies, our study has several limitations. A selection bias cannot be eliminated due to the method of data collection via email from the German Society for Dentistry, Oral and Maxillofacial Medicine. Most importantly, various factors could influence the objectivity of the answers, as the participating head of department or private practice owner provided an assessment for the entire facility.

\section{Conclusions}

The rate of infection among HCWs was significantly higher in private practices than in hospital wards, and significantly higher in large practices than in small practices. Preinterventional testing was implemented in only a few dental facilities, and therefore this requires improvement. Ventilation systems were used in approximately half of the dental practices, and their use should be expanded. Finally, the economic impact of the pandemic on dental facilities was evident; however, the number of employees in most facilities remained unchanged during the pandemic.

Supplementary Materials: The following are available online at https:/ / www.mdpi.com/article/10 .3390/ijerph19010175/s1. Figure S1: Questionnaire.

Author Contributions: Conceptualization, S.Z., E.B., A.M. (Anna Muzalyova), A.E., M.K., H.M. and C.R.; data curation, S.Z., E.B., A.M. (Anna Muzalyova), A.E., M.K., C.T.-H., R.F., F.M.E., T.Z., A.M. (Axel Meisgeier), H.M., C.R. and T.S.; formal analysis, A.E., C.T.-H., R.F. and H.M.; funding acquisition, A.E., H.M. and C.R.; investigation, H.M. and T.S.; methodology, S.Z. and A.M. (Anna Muzalyova); resources, C.T.-H., R.F., H.M. and T.S.; supervision, H.M., C.R. and T.S.; validation, C.T.-H., R.F., F.M.E. and T.Z.; visualization, A.M. (Anna Muzalyova); writing-original draft, S.Z., E.B., A.M. (Anna Muzalyova), C.R. and T.S.; writing-review and editing, A.E., C.T.-H., R.F., F.M.E., T.Z., A.M. (Axel Meisgeier) and H.M. All authors have read and agreed to the published version of the manuscript.

Funding: This study received public funds from B-FAST of the Network of University Medicine (NUM) (Award/Grant Number: 01KCX2021) and the Bavarian State Ministry for Science and Arts (Award/Grant Number: 152820012).

Institutional Review Board Statement: This study was conducted in accordance with the Declaration of Helsinki and the Good Clinical Practice (GCP) guidelines. A positive ethical evaluation was obtained from the Ethics Committee of the Faculty of Medicine of the Technical University of Munich under the accession number $713 / 20$ S-SR.

Informed Consent Statement: Informed consent was obtained from all subjects involved in the study. 
Data Availability Statement: Data can be obtained from the corresponding author on request.

Conflicts of Interest: The authors declare that they have no conflict of interest.

\section{References}

1. Cucinotta, D.; Vanelli, M. WHO Declares COVID-19 a Pandemic. Acta Biomed. 2020, 91, 157-160. [PubMed]

2. Budweiser, S.; Baş, S.; Jörres, R.A.; Engelhardt, S.; Thilo, C.; Delius, S.V.; Eckel, F.; Biller, U.; Lenherr, K.; Deerberg-Wittram, J.; et al. Comparison of the First and Second Waves of Hospitalized Patients with SARS-CoV-2. Dtsch. Arztebl. Int. 2021, 118, 326-327. [PubMed]

3. Aufklärung, B.F.G. Bundeszentrale für Gesundheitliche Aufklärung. 2021. Available online: https://www.infektionsschutz.de/ coronavirus/alltag-in-zeiten-von-corona.html (accessed on 12 May 2021).

4. Erdem, H.; Lucey, D.R. Healthcare worker infections and deaths due to COVID-19: A survey from 37 nations and a call for WHO to post national data on their website. Int. J. Infect. Dis. 2021, 102, 239-241. [CrossRef] [PubMed]

5. Dong, E.; Du, H.; Gardner, L. An interactive web-based dashboard to track COVID-19 in real time. Lancet Infect. Dis. 2020, 20, 533-534. [CrossRef]

6. Supady, A.; Curtis, J.R.; Abrams, D.; Lorusso, R.; Bein, T.; Boldt, J.; Brown, C.E.; Duerschmied, D.; Metaxa, V.; Brodie, D.; et al. Allocating scarce intensive care resources during the COVID-19 pandemic: Practical challenges to theoretical frameworks. Lancet Respir. Med. 2021, 9, 430-434. [CrossRef]

7. Melman, G.J.; Parlikad, A.K.; Cameron, E.A.B. Balancing scarce hospital resources during the COVID-19 pandemic using discrete-event simulation. Health Care Manag. Sci. 2021, 24, 356-374. [CrossRef] [PubMed]

8. Schwaben, Z.B. Zahnärztliche Nachrichten Schwaben. April 2020. Ausgabe 4-20. Available online: https://www.zbv-schwaben. de/wp-content/uploads/2020/03/ZNS-4-2020.pdf (accessed on 13 November 2021).

9. Gallagher, J.E.; Sukriti, K.C.; Johnson, I.G.; Al-Yaseen, W.; Jones, R.; McGregor, S.; Robertson, M.; Harris, R.; Innes, N.; Wade, W.G. A systematic review of contamination (aerosol, splatter and droplet generation) associated with oral surgery and its relevance to COVID-19. BDJ Open 2020, 6, 1-17. [CrossRef] [PubMed]

10. Khader, Y.; Nsour, M.A.; Al-Batayneh, O.B.; Saadeh, R.; Bashier, H.; Alfaqih, M.; AlShurman, B.A.; Abed, R.E.; Alkhatib, Z.; Samaranayake, L.P. Dentists' Awareness, Perception, and Attitude Regarding COVID-19 and Infection Control: Cross-Sectional Study among Jordanian Dentists. JMIR Public Health Surveill. 2020, 6, e18798. [CrossRef] [PubMed]

11. Jamal, M.; Shah, M.; Almarzooqi, S.H.; Aber, H.; Khawaja, S.; El Abed, R.; Alkhatib, Z.; Samaranayake, L.P. Overview of transnational recommendations for COVID-19 transmission control in dental care settings. Oral Dis. 2021, 27 (Suppl. 3), 655-664. [CrossRef] [PubMed]

12. Bundeszahnärztekammer. Klartext 10/19. Available online: https://www.bzaek.de/fileadmin/PDFs/klartext/19/191029_KT_ 10.pdf (accessed on 13 November 2021).

13. Boger, B.; Fachi, M.M.; Vilhena, R.O.; Cobre, A.F.; Tonin, F.S.; Pontarolo, R. Systematic review with meta-analysis of the accuracy of diagnostic tests for COVID-19. Am. J. Infect. Control 2021, 49, 21-29. [CrossRef] [PubMed]

14. DGZMK. Umgang Mit Zahnmedizinischen Patienten Bei Belastung Mit Aerosol-übertragbaren Erregern, Langversion, 2020, AWMF-Registiernummer: 083-046. Available online: https://www.awmf.org/leitlinien/detail/II/083-046.html (accessed on 13 November 2021).

15. Barabari, P.; Moharamzadeh, K. Novel Coronavirus (COVID-19) and Dentistry-A Comprehensive Review of Literature. Dent. J. 2020, 8, 53. [CrossRef] [PubMed]

16. Römmele, C.; Ebigbo, A.; Kahn, M.; Zellmer, S.; Muzalyova, A.; Hammel, G.; Bartenschlager, C.; Beyer, A.; Rosendahl, J.; Schlittenbauer, T.; et al. Health-care workers in gastrointestinal endoscopy are at higher risk for SARS-CoV-2 infection compared to other aerosol-generating disciplines. MedRxiv 2021. [CrossRef]

17. Sozkes, S.; Olszewska-Czyz, I. Effects of COVID-19 Pandemic on Working Conditions of Dentists in Poland and Turkey. Medicina 2021, 57, 1082. [CrossRef] [PubMed]

18. Sinjari, B.; Rexhepi, I.; Santilli, M.; D'Addazio, G.; Chiacchiaretta, P.; Carlo, P.D.; Caputi, S. The Impact of COVID-19 Related Lockdown on Dental Practice in Central Italy-Outcomes of A Survey. Int. J. Environ. Res. Public Health 2020, 17, 5780. [CrossRef] [PubMed]

19. DGZMK. Umgang Mit Zahnmedizinischen Patienten bei Belastung Mit Aerosol-übertragbaren Erregern, Langfassung 2.0, 2021, AWMF-Registiernummer: 083-046. Available online: https:/ /www.awmf.org/leitlinien/detail/1l/083-046LG.html (accessed on 13 November 2021).

20. Tzoutzas, I.; Maltezou, H.C.; Barmparesos, N.; Tasios, P.; Efthymiou, C.; Assimakopoulos, M.N.; Tseroni, M.; Vorou, R.; Tzermpos, F.; Antoniadou, M.; et al. Indoor Air Quality Evaluation Using Mechanical Ventilation and Portable Air Purifiers in an Academic Dentistry Clinic during the COVID-19 Pandemic in Greece. Int. J. Environ. Res. Public Health 2021, 18, 8886. [CrossRef] [PubMed]

21. Ren, Y.-F.; Huang, Q.; Marzouk, T.; Richard, R.; Pembroke, K.; Martone, P.; Venner, T.; Malmstrom, H.; Eliav, E. Effects of mechanical ventilation and portable air cleaner on aerosol removal from dental treatment rooms. J. Dent. 2021, 105, 103576. [CrossRef] [PubMed]

22. Teichert-Filho, R.; Baldasso, C.N.; Campos, M.M.; Gomes, M.S. Protective device to reduce aerosol dispersion in dental clinics during the COVID-19 pandemic. Int. Endod. J. 2020, 53, 1588-1597. [CrossRef] [PubMed] 
23. Sarapultseva, M.; Hu, D.; Sarapultsev, A. SARS-CoV-2 Seropositivity among Dental Staff and the Role of Aspirating Systems. JDR Clin. Trans. Res. 2021, 6, 132-138. [CrossRef] [PubMed]

24. Schwendicke, F.; Krois, J.; Gomez, J. Impact of SARS-CoV2 (COVID-19) on dental practices: Economic analysis. J. Dent. 2020, 99, 103387. [CrossRef] [PubMed]

25. Wolf, T.G.; Deschner, J.; Schrader, H.; Bührens, P.; Kaps-Richter, G.; Cagetti, M.G. Dental Workload Reduction during First SARS-CoV-2/COVID-19 Lockdown in Germany: A cross-sectional Survey. Int. J. Environ. Res. Public Health 2021, $18,3164$. [CrossRef]

26. KZVB, E. March 22nd 2021 Statement, “Pandemiezuschlag” für Vertragszahnärztliche Praxen. Available online: https:/ /www. kzbv.de/informationen-fuer-praxen.1371.de.html (accessed on 19 May 2021).

27. Robert-Koch-Institut, Impfquotenmonitoring. Available online: https://www.rki.de/DE/Content/InfAZ/N/Neuartiges_ Coronavirus/Daten/Impfquoten-Tab.html (accessed on 21 June 2021). 